\title{
Morphological characteristic of the membranous nephropathy Tulepbergenov $\mathbf{N}$. Морфологическая характеристика мембранозной нефропатии Тулепбергенов Н. Б.
} Тулепбергенов Нуржан Бакытович / Tulepbergenov Nurzhan - врач-патологоанатом,
Республиканское патологоанатомическое бюро, г. Бишкек, Кыргызская Республика

\begin{abstract}
Аннотация: материалом исследования послужили 145 биоптатов почек. При исследовании нефробиоптатов использовали гистологический, гистохимический, иммуногистохимический, электронномикроскопический методы. Мембранозная нефропатия обнаружена у 14 больных (9,6\%) - 11 мужчин и три женщины в возрасте 22,0 \pm 3,35 лет. Мембранозная нефропатия чаше встречается $у$ жителей высокогорья, чем у жителей низкогорья. Отмечается преобладание больных мужского пола, молодого возраста. Мембранозная нефропатия является иммунологически обусловленной невоспалительной гломерулопатией, имеет прогрессирующее стадийное течение. При комплексном морфологическом исследовании у 4 больных обнаружена I стадия мембранозной нефропатии, у 5 - II стадия, у 5- III стадия. В первой стадии мембранозной нефропатии отмечается минимальное утолщение гломерулярной базальной мембраны с нежной «пунктирностью». В небольшом количестве определяются субэпительальные депозиты. Во второй стадии отмечается грубая «пунктирность» гломерулярной базальной мембраны. В клубочках встречается склероз отдельных капиллярных петель и синехии с капсулой. Субэпителиальные депозиты разделяются выростами гломерулярной базальной мембраны в виде «иипиков». В третьей стадии мембранозной нефропатии происходит выраженное диффузное утолщение, удвоение и расщепление гломерулярной базальной мембраны. Депозить окружены веществом гломерулярной базальной мембраны, наблюдается лизис отдельных депозитов. При имунногистохимическом исследовании определяется диффузная гранулярного характера фиксация, чаме Ig $G$ и $M$.

Abstract: 145 bioptat of kidneys have served as material of a research. At a research of nefrobioptat used histologic, histochemical, immunohistochemical, elektronnomikroskopichesky methods. The membranozny nephropathy is found in 14 patients (9,6\%) - 11 men and three women at the age of 22,0 $\pm 3,35$ years. The membranozny nephropathy meets at inhabitants of highlands more often, than inhabitants have nizkogorye. Prevalence of male patients, young age is noted. The Membranozny nephropathy is immunological the caused not inflammatory glomerulopatiya, has the progressing phasic current. At a complex morphological research the I stage of a membranozny nephropathy, at 5 - the II stage, at 5-III stage is found in 4 patients. In the first stage of a membranozny nephropathy the minimum thickening of a glomerulyarny basal membrane with gentle "punktirnost" is noted. In a small amount subepitelyalny deposits are defined. In the second stage rough "punktirnost" of a glomerulyarny basal membrane is noted. In balls the sclerosis of separate capillary loops and a sinekhiya meets the capsule. Subepitelialny deposits are divided by outgrowths of a glomerulyarny basal membrane in the form of "shipik". In the third stage of a membranozny nephropathy there is an expressed diffusion thickening, doubling and splitting of a glomerulyarny basal membrane. Deposits are surrounded with substance of a glomerulyarny basal membrane, the lysis of separate deposits is observed. At an imunnogistokhimichesky research diffusion fixing of granular character is defined, Ig G and M is more often.
\end{abstract}

Ключевые слова: биопсия, мембранозная нефропатия.

Keywords: biopsy, membranous nephropathy.

Актуальность: мембранозная нефропатия (МН) впервые описана E. Bell в 1929 г. А в 1957 году Р. Jones предложил термин «мембранозный гломерулонефрит». МН в литературе известна под несколькими названиями: идиопатический мембранозный гломерулонефрит, мембранозная гломерулопатия, непролиферативный гломерулонефрит $[5,6]$. Отсутствие ярких признаков воспалительной реакции в клубочках при МН, отражающей сущность группового понятия «гломерулонефрит» дало основание некоторым авторам отнести его к невоспалительным гломерулопатиям и выделить в группу первичного нефротического синдрома $[2,3]$. МН является основной причиной нефротического синдрома у взрослых и часто становится причиной развития хронической почечной недостаточности [3, 6]. В Кыргызстане комплексное морфологическое исследование МН не проводилось.

Цель исследования: Изучить морфологическую характеристику мембранозной нефропатии.

МАТЕРИАЛ И МЕТОДЫ ИССЛЕДОВАНИЯ

Материалом исследования послужили 145 биоптатов почек, проведенных в Национальном центре кардиологии и терапии и исследованных в Республиканском патологоанатомическом бюро Министерства Здравоохранения Кыргызской Республики. При исследовании нефробиоптатов использовали гистологический, гистохимический, иммуногистохимический, 
электронномикроскопический методы. Иммуногистохимическое (ИГ) и электронномикроскопическое (ЭМ) исследования проводились в лаборатории иммунногистохимии и электронной микроскопии Московской медицинской академии имени И. М. Сеченова (Приносим глубокую признательность профессору Варшавскому В. А и к.м.н. Голициной Е. П. за помощь в проведении данных исследований).

\section{РЕЗУЛЬТАТЫ ИССЛЕДОВАНИЯ}

Среди 145 больных 60 (41,4\%) проживали в низкогорье (г. Бишкек, районы Чуйской долины, расположенные на высоте ниже 1500 м. над уровнем моря). В условиях высокогорья (районы Кыргызской Республики с высотой 2400 м. и выше) проживали 85 (58,6\%) больных (табл. 1).

Таблииа 1. Морфологические варианты гломерулопатий

\begin{tabular}{|c|c|c|c|c|c|c|}
\hline \multirow[t]{2}{*}{ Морфологические вариантыГП } & \multicolumn{2}{|c|}{ Высокогорье } & \multicolumn{2}{|c|}{ Низкогорье } & \multicolumn{2}{|c|}{ ВСЕГО } \\
\hline & Aбc. & $\%$ & Абс. & $\%$ & Абс. & $\%$ \\
\hline Мембранозная нефропатия & 10 & 16,6 & 4 & $4,7 *$ & 14 & 9,6 \\
\hline Минимальные изменения & 0 & 0 & 5 & 5,8 & 5 & 3,4 \\
\hline $\begin{array}{cc}\text { Фокальный } & \text { сегментарный } \\
\text { гломерулосклероз } & \\
\end{array}$ & 0 & 0 & 2 & 2,4 & 2 & 1,3 \\
\hline $\begin{array}{l}\text { Мезангиопроли- } \\
\text { феративный ГН }\end{array}$ & 32 & 53,4 & 44 & 51,7 & 76 & 52,5 \\
\hline $\begin{array}{l}\text { Мезангиокапиллярный } \\
\text { ГН }\end{array}$ & 18 & 30,0 & 30 & 35,3 & 48 & 33,2 \\
\hline Итого & 60 & 100,0 & 85 & 100,0 & 145 & 100,0 \\
\hline
\end{tabular}

Примечание: Абс. - абсолютное количество, * $-\mathrm{p}<0,05$ при сравнении встречаемости морфологических вариантов ГП на разных высотах.

МН обнаружена у 14 больных (9,6\%), среди которых было 11 мужчин и три женщины в возрасте 22,0 $\pm 3,35$ лет, что согласуется с данными других авторов [8]. При комплексном морфологическом исследовании у 4 больных обнаружена I стадия МН, у 5 - II стадия, у 5 - III стадия.

І-стадия (4 наблюдения). При светооптическом (СО) исследовании отмечается минимальное диффузное утолщение гломерулярной базальной мембраны (ГБМ), в отдельных клубочках отмечается незначительная очаговая пролиферация мезенгиальных клеток. Выявляется нежная «пунктирность» ГБМ (рис. 1а). При ИГ исследовании во всех наблюдениях обнаружена диффузная гранулярного характера фиксация IgG на ГБМ (рис. 1б). При ЭМ исследовании на эпителиальной стороне ГБМ выявлялись очень мелкие и в небольшом количестве гранулы электронноплотного материала, хорошо отграниченные от laminadensa ГБМ тонким слоем laminararaexterna (рис. 1в).
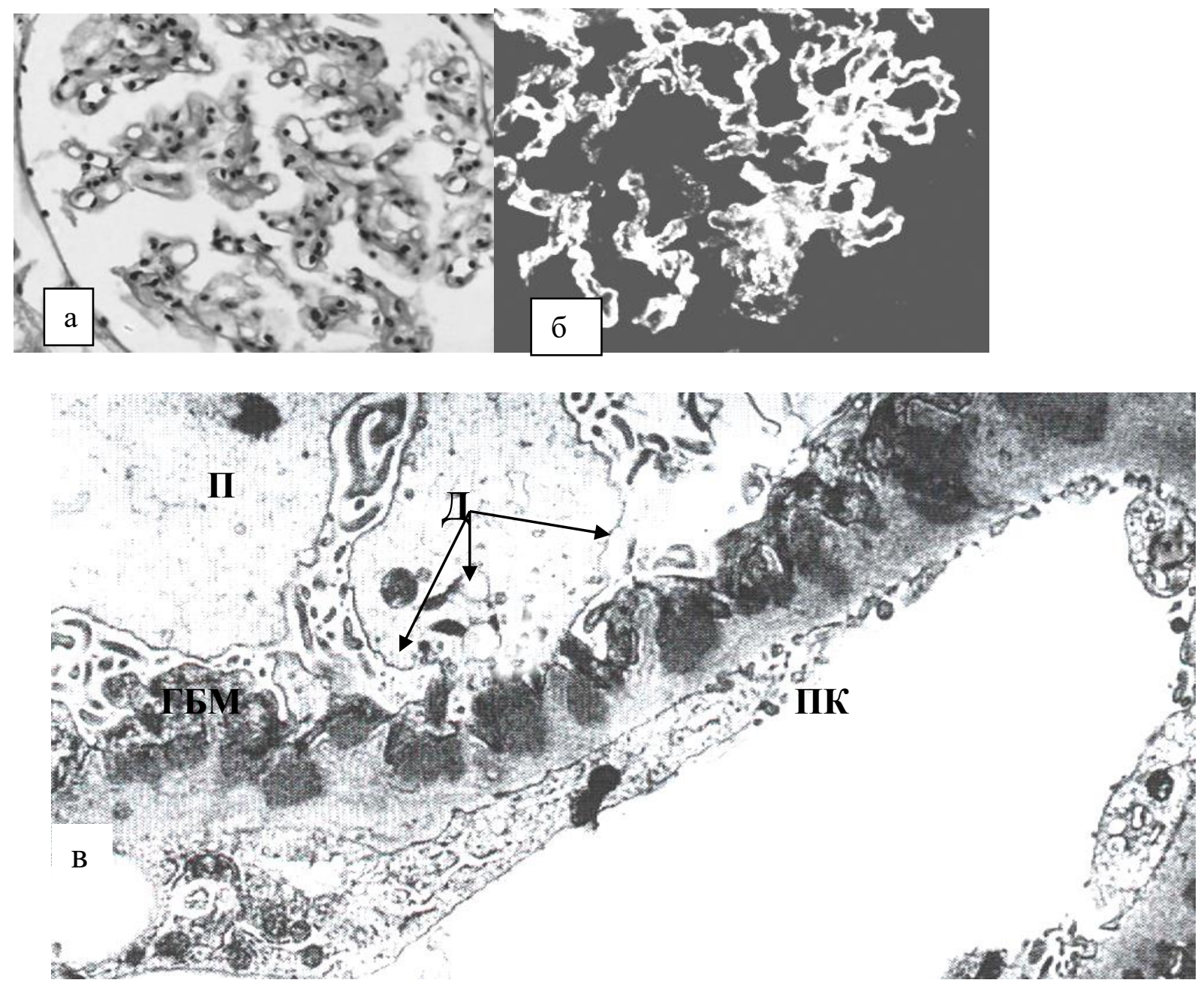
Рис. 1. Мембранозная нефропатия. I- стадия.

$a$ - диффузное незначительное утолщение гломерулярной базальной мембраны (ГБМ), без пролиферации мезангиальных клеток. Окраска гематоксилином и эозином, $x 400$.

б- иммунные депозиты диффузно гранулярного характера на ГБМ, содержащие Ig G. Прямой метод Кунса, $x 250$. в - субэпителиальные депозиты (Д) зернистой структуры, подоичиты (П) распластаны по ГБМ. Электронограмма, $x 10000$

II-стадия (5 наблюдений). При СО исследовании отмечено диффузное однородное утолщение ГБМ, определяется грубая «пунктирность» ГБМ и «шипики», отходящие от ГБМ в сторону эпителия (рис. 2a). В клубочках встречается склероз отдельных капиллярных петель, их единичные синехии с капсулой клубочка. При ИГ исследовании обнаружено свечение Ig G диффузно гранулярного характера на ГБМ (рис 2б). При ЭМ исследовании на эпителиальной стороне ГБМ определяется множество отложений электронноплотного материала в виде гранул, разделенных выростами laminadensa ГБМ, в результате чего ГБМ имела вид гребня, гранулы электронноплотного материала диффузно распределены по ГБМ всех капилляров (рис. 2г).
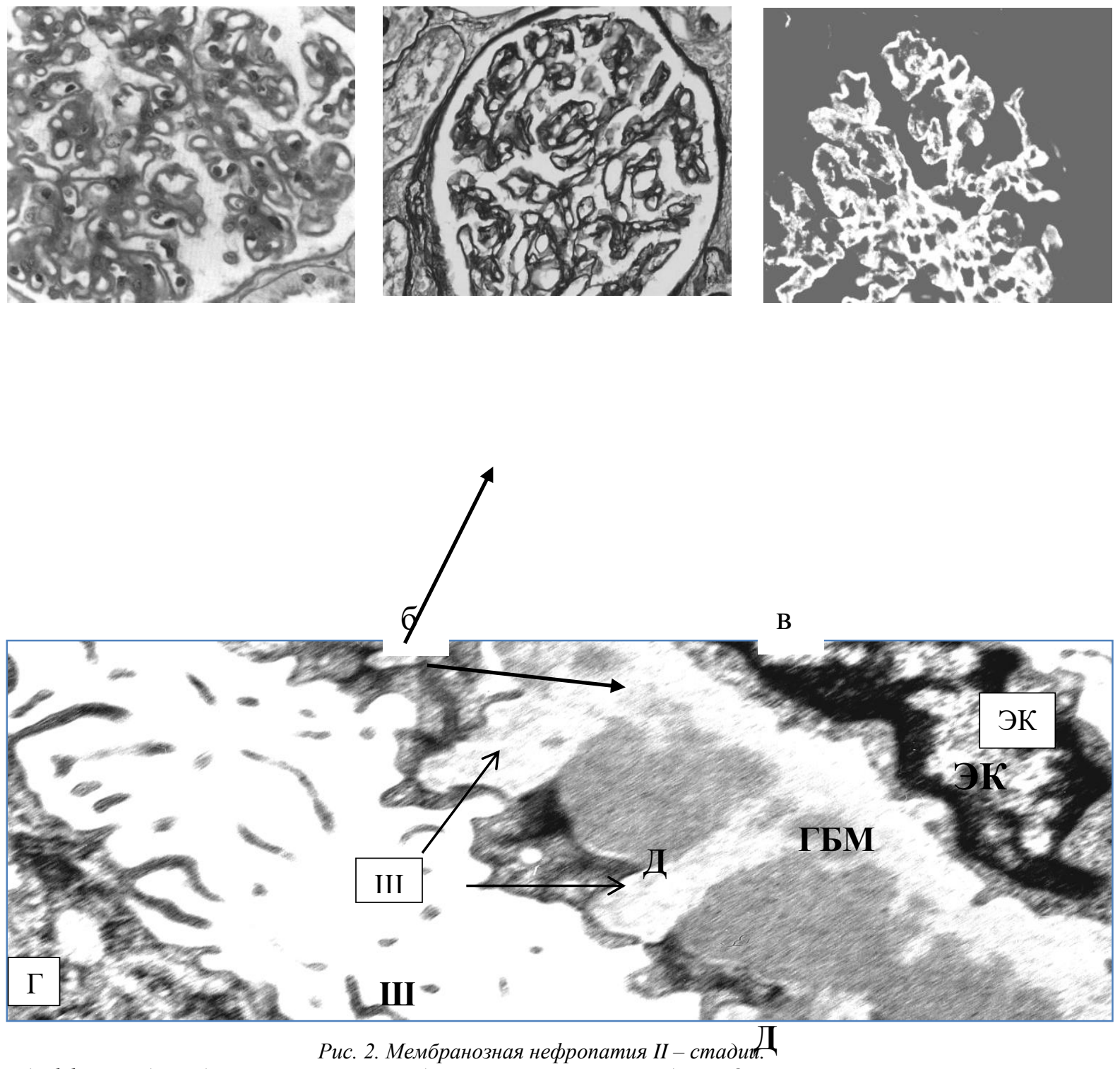

$a$ - диффузное однородное утолщение ГБМ, без гиперклеточности клубочка. Окраска гематоксилином и эозином, $x$ 400.

б - «пунктирность» ГБМ, склероз отдельных капиллярных петель. PAS-реакиия, х 400. в-иммунные депозиты диффузно гранулярного характера на ГБМ, содержашие Ig G. Прямой метод Кунса, $x 250$. 2-субэпителиальные депозиты (Д) разделены выростами laminadensa ГБМ в виде «шипиков» (Ш). 
III-стадия (5 наблюдений). При СО исследовании характеризовалась дальнейшим выраженным диффузным утолщением и неравномерным окрашиванием ГБМ. (рис. 3а, б). В строме выявляются «пенистые клетки» (рис. 3в). Определяются поля грубой «пунктирности» и «шипики», преобладание удвоения и расщепления ГБМ, образование так называемых мостиков между расщепленными частями ГБМ. При ИГ исследовании в одном наблюдении специфического свечения не обнаружено, в 4 наблюдениях выявлено обильное отложение Ig G, в 9- Ig M, в 3- Ig А на ГБМ диффузно гранулярного характера. При ЭМ исследовании отмечается неравномерное утолщение ГБМ, отложения электронноплотного материала окружены веществом ГБМ, имеют зернистую структуру и меньшую электронную плотность, чем в первой и второй стадиях (рис. Зг).
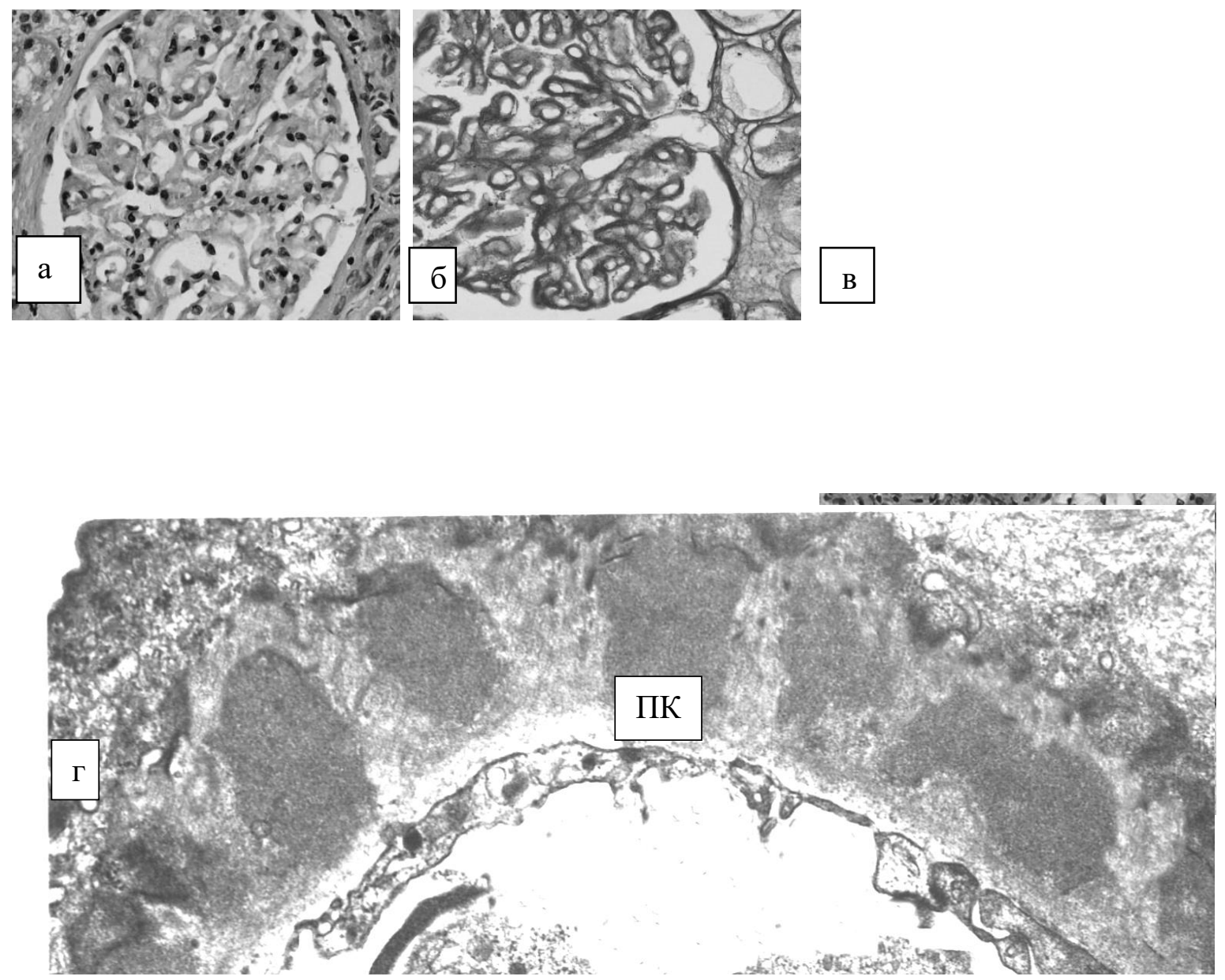

Рис. 3. Мембранозная нефропатия III- стадии.

$a$ - выраженное диффузное утолщение, «пунктирность» ГБМ; синехии между капиллярными петлями и капсулой клубочка. Окраска гематоксилином и эозином, 400.

б - «пунктирность», удвоение и расщепление ГБМ. РАS - реакиия, $x 400$.

в - «пенистые клетки» в строме коркового слоя. Окраска гематоксилином и эозином, х 200.

г - ГБМ утолщена, депозиты окружены веществом ГБМ, лизис отдельных депозитов. Электронограмма, х 18000

\section{ЗАКЛЮЧЕНИЕ}

Таким образом, наше исследование показало, что мембранозная нефропатия чаще встречается у жителей высокогорья, чем у жителей низкогорья. Отмечается преобладание больных мужского пола, молодого возраста. Мембранозная нефропатия является иммунологически обусловленной невоспалительной гломерулопатией, имеет прогрессирующее стадийное течение и характеризуется дистрофическими и склеротическими процессами.

\section{Лuтература}

1. Мухин Н.А., Козловская Л. В. Мембранозная нефропатия: как дифференцировать первичный и вторичный варианты. Клиническая нефрология, 2009. 2: 75-78.

2. Серов В. В. Эволюция понятия «гломерулонефрит» // Клин. мед., 2000. 9. Стр. 5-7. 
3. Серов В. В., Пальщеев М. А., Иванов А. А., Варшавский В. А. Современные подходы к классификации гломерулонефрита // Арх. пат., 1999. 5. Стр. 38-40.

4. Agarwal S. K., Dash S. C. Spectrum of renal diseases in Indian adults // J. Assoc. Physicians India, 2000. Vol. 48 (6). p. 594-600.

5. Briganti E. M., Dowling J., Finlay M. et al. The incidence of biopsy-proven glomerulonephritis in Australia // Nephrol. Dial. Transplant, 2001. Vol. 16 (7). P. 1364-7.

6. Dhiman R. K., Poddar U., Sharma B. C. et al. Membranous glomerulonephritis in association with ulcerative colitis // Indian J. Gastroenterol., 1998. Vol. 17(2). P. 62.

7. Dumoulin A., Hill G.S., Montseny J.J., Meyrier A. Clinical and morphological prognostic factors in membranous nephropathy: significance of focal segmental glomerulosclerosis // Am. J. Kidney Dis., 2003. Vol. 41 (1). P. 38-48.

8. Ponticelli C. Membranous nephropathy. J Nephrol, 2007. 20 (3). 268-287. 